\title{
NECESSIDADES E REIVINDICAÇÕES DE HOMENS TRABALHADORES RURAIS FRENTE À ATENÇÃO PRIMÁRIA À SAÚDE
}

\author{
NEEDS AND DEMANDS OF MALE RURAL WORKERS \\ REGARDING PRIMARY HEALTH CARE
}

\begin{abstract}
Sérgio Vinícius Cardoso de Miranda ${ }^{1}$ (D) [0000-0002-8482-7560], Pâmela Scarlatt Durães Oliveira $^{2}$ (D) [0000-0001-6084-5011] Virlady Cardoso de Miranda Moraes ${ }^{3}$ (iD) [0000-0001-86833588], Luiz Carlos Fadel de Vasconcellos ${ }^{4}$ (iD) [0000-0002-7679-9870]
\end{abstract}

\author{
${ }^{1}$ Escola Nacional de Saúde Pública Sergio Arouca, Fundação Oswaldo Cruz, Rio de Janeiro, Brasil. \\ <sergio.vinicius.esf@gmail.com> \\ ${ }^{2}$ Universidade Estadual de Montes Claros, Programa de Pós-Graduação em Ciências da Saúde, Montes \\ Claros, MG, Brasil. \\ ${ }^{3}$ Prefeitura Municipal de Japonvar, Secretaria Municipal de Saúde, Núcleo de Apoio à Saúde da Família, \\ Japonvar, MG, Brasil. \\ ${ }^{4}$ Fundação Oswaldo Cruz, Escola Nacional de Saúde Pública Sergio Arouca, Rio de Janeiro, RJ, Brasil.
}

Resumo O objetivo foi compreender as principais necessidades e reivindicações de homens trabalhadores rurais frente a uma equipe de Atenção Primária à Saúde, Japonvar, MG, Brasil. Trata-se de um estudo qualitativo, guiado pela abordagem hermenêutica-dialética. Foram realizadas 41 entrevistas em profundidade, registros em diário de campo e coleta de dados secundários. Na análise, utilizamos os níveis de interpretação, permitindo a construção de duas categorias temáticas para as necessidades de saúde: 'aumento no fornecimento de medicamentos' e 'acesso a exames especializados e específicos para a próstata'. Também foram desenvolvidas duas categorias para as reivindicações sociais: 'reconhecimento como usuários do serviço de saúde' e 'grupos de educação em saúde com temáticas masculinas'. A discussão foi alicerçada nos atributos da Atenção Primária à Saúde e na Teoria dos Marcadores Sociais e Interseccionalidades. O estudo possibilitou compreender o processo produtivo, conhecer as características clínico-epidemiológicas e discutir a invisibilidade dos trabalhadores rurais na procura e acesso aos serviços de saúde. Observamos uma valorização do modelo assistencial curativista e a contribuição positiva das reivindicações dos homens para o fortalecimento dos movimentos de luta pelo direito social à saúde.

Palavras-chave população rural; atenção primária à saúde; saúde do homem; necessidades e demandas de serviços de saúde.
Abstract The aim was to understand the main needs and demands of male rural workers regarding a Primary Health Care team in Southeastern Brazil. It is a qualitative study, which was guided by the hermeneutic-dialectical approach. We conducted 41 in-depth interviews, recorded notes on field journals, and collected secondary data. In the analysis, we used the levels of interpretation, which enabled the development of two thematic categories for the health needs: "increase in the supply of medicines" and "access to specialized and specific prostate exams." We also developed two categories for the social demands: "acknowledgment as users of the health service" and "education in health groups dealing with male issues." The discussion was based on the attributes of Primary Health Care and on the Social Markers and Intersectionality Theory. The study enabled us to comprehend the production process, to get to know the clinical-epidemiological characteristics, and to discuss the invisibility of the rural workers in the demand for and access to health services. We observed a high regard for the curative care model, and the positive contribution of the demand of the men to the strengthening of the movements of struggle for the right to social health.

Keywords rural population; primary health care; male health; needs and demands for health services. 


\section{Introdução}

O ser humano possui, ao longo da vida, necessidades básicas que são determinadas e constituídas pela organização de seu cotidiano, por sua identidade cultural e pelas relações sociais e históricas que o atravessam. De acordo com Heller (1986), o homem cria ao mesmo tempo suas necessidades e os meios para satisfazê-las. No capitalismo, o termo necessidade está relacionado diretamente a interesses privados e à produção de mais-valia. Nesse sentido, as necessidades são concretizadas de maneira desigual e determinadas com base na inserção e na posição que cada indivíduo ocupa na sociedade.

Segundo Campos (2004), o tema das necessidades de saúde tem sido foco de diversos estudos na Saúde Coletiva, sendo divididos em dois grandes grupos: o primeiro no âmbito abstrato de cada indivíduo e o segundo no domínio operacional do planejamento em saúde. A satisfação das necessidades de saúde não indica apenas necessidades de consultas médicas, tratamento de doenças, atendimentos de saúde, sofrimentos ou riscos (Yonekura, 2016).

As necessidades de saúde também estão relacionadas à presença do Estado na oferta de políticas públicas, à participação da sociedade civil na luta pela garantia dos direitos universais e ao acesso a ações e serviços públicos para as populações que habitam os diversos territórios e que apresentam diferentes condições de vida e trabalho (Campos e Mishima, 2005).

As reivindicações sobre determinada demanda popular são concebidas para afirmar que não há política pública desligada de lutas sociais. A organização de classe e a reprodução social devem ser consideradas como movimentos de resistência contra a dominação do Estado (Piana, 2009). Nessa abordagem, os problemas de saúde devem ser vistos na perspectiva da inclusão ou exclusão social, em que os impactos da estrutura social sobre a saúde são pensados por meio das vulnerabilidades associadas aos territórios e às posições sociais (Barata, 2009).

O território rural é um espaço com baixa densidade populacional e que apresenta características de pluriatividade, multissetorialidade e multifuncionalidade (Kageyma, 2008). A população rural deve ser compreendida pelas suas inter-relações sociais, produtivas, econômicas e políticas e não simplesmente como uma população que reside em uma área não urbanizada. Dentre as principais funções desses territórios estão a sustentabilidade ecológica, a produção agropecuária e a organização social de grupos populacionais, como os trabalhadores rurais e suas famílias.

A categoria trabalho rural engloba atividades que são realizadas por conta própria pelo trabalhador rural em sua propriedade ou como arrendatário, parceiro ou meeiro. O trabalho rural é considerado como um modo de produzir e fazer agricultura, marcado por grandes desigualdades no acesso e posse da terra, nas relações de produção com a introdução de novas tecnologias e no valor e destino da produção (Nascimento, 2007). 
De acordo com Silva e Portella (2006), o trabalho no meio rural apresenta o entrecruzamento das relações sociais de gênero, classe e geração. Nesse sentido, as relações sociais no meio rural são perpassadas pela dinâmica do trabalho na agricultura, realizado, majoritariamente, por homens de baixa renda. No trabalho rural, as relações e decisões diversas do cotidiano familiar, tanto no espaço público quanto no privado são, muitas vezes, oriundas de um modelo de relações hierárquicas entre homens e mulheres, no qual a figura masculina representa o centro das decisões e do poder.

Em relação à saúde, historicamente, as populações do campo sempre enfrentaram uma descontinuidade de modelos assistenciais e de políticas públicas de saúde que não se consolidaram (Caldart et al., 2012). Questões como a baixa escolaridade, desigualdade de renda, condições precárias de moradia, sobrecarga de trabalho e dificuldades de transporte continuam contribuindo para os altos níveis de exclusão e discriminação dessa população pelos serviços de saúde.

Quando falamos em saúde no campo, torna-se fundamental o resgate do conceito de Atenção Primária à Saúde (APS). Para Starfield (2002), a APS deve ser a porta de entrada dos usuários no sistema de serviços de saúde, de forma a satisfazer as principais necessidades e as condições de saúde mais prevalentes. Para isso, a APS deve fornecer uma atenção continuada e de base geográfica, por meio de um conjunto de intervenções individuais e coletivas, que envolvem a promoção, a prevenção, o diagnóstico, o tratamento e a reabilitação.

A APS orienta-se por quatro atributos essenciais - atenção ao primeiro contato, longitudinalidade, integralidade e coordenação - e três derivados orientação familiar, orientação comunitária e competência cultural (Starfield, 2002). Por meio desses sete atributos, a rede de serviços do Sistema Único de Saúde (SUS) deve assumir a função central de acolher, escutar e oferecer uma resposta positiva a todos os usuários, com o objetivo de resolver a maioria dos problemas de saúde de determinados territórios.

Uma grande questão enfrentada diz respeito à organização das ações programáticas da APS. Estas tendem a privilegiar os mesmos grupos populacionais com a implantação de agendas específicas para as áreas de saúde da mulher, saúde da criança, saúde do adulto - com foco nos hipertensos e diabéticos e saúde do idoso (Silva et al., 2012). Nessas ações, a saúde do trabalhador e, principalmente, a saúde do homem têm sido pouco favorecidas e dotadas de uma lenta evolução.

Este artigo buscou, então, compreender as principais necessidades e reivindicações de homens trabalhadores rurais frente a uma equipe de Atenção Primária à Saúde situada em um território do norte de Minas Gerais, Brasil. Diante desta conjuntura, é fundamental destacarmos duas questões para a APS: a organização de práticas de saúde mais democráticas para o público 
masculino e a viabilidade de acesso aos serviços, considerando o meio social em que estão inseridos e o seu processo de trabalho.

\section{Método}

Trata-se de um estudo qualitativo ${ }^{1}$, guiado teoricamente pela hermenêuticadialética de base materialista histórica. Por meio da hermenêutica, ocorre a compreensão dos sentidos, tendo na linguagem seu núcleo central. A dialética busca, nos fatos e na cultura, os núcleos enigmáticos e contraditórios para realizar uma crítica sobre eles (Habermas, 1987; Gadamer, 1999). A união da hermenêutica com a dialética possibilita uma reflexão da realidade social pesquisada (Minayo, 2014).

Foram selecionados homens, na faixa etária de 18 a 60 anos, que desempenhavam o trabalho rural como principal atividade por um período mínimo de um ano e que estivessem cadastrados na equipe de APS da comunidade rural de Nova Minda, no município de Japonvar. O município está localizado ao norte do estado de Minas Gerais, Brasil, a $96 \mathrm{~km}$ de Montes Claros, cidadepolo da macrorregião e a $535 \mathrm{~km}$ da capital, Belo Horizonte. Segundo o Instituto Brasileiro de Geografia e Estatística (IBGE, 2016), a cidade apresentava uma população de, aproximadamente, 8.298 habitantes, com predominância rural, em que 3.050 pessoas residiam na zona urbana $(36,8 \%)$ e 5.248 , na zona rural $(63,2 \%)$.

A comunidade de Nova Minda encontra-se $22 \mathrm{~km}$ distante da sede do município, com 1.958 habitantes, sendo considerada o maior distrito da região. A economia baseia-se nas atividades primárias, em pequenas propriedades rurais, com predomínio da agricultura familiar, pecuária, o extrativismo do fruto do pequi e a fabricação de biscoitos caseiros. A cidade é conhecida como a 'capital do pequi e do biscoito', onde, no mês de junho, é realizada a tradicional Festa Nacional do Biscoito.

A coleta dos dados ocorreu no período de maio a julho de 2016, com a realização de 41 entrevistas individuais em profundidade, coleta de informações nos prontuários dos entrevistados e registros em um diário de campo dos fatos mais relevantes durante o contato com os entrevistados. As entrevistas foram previamente agendadas pelos Agentes Comunitários de Saúde (ACS), com a supervisão dos pesquisadores, para serem realizadas na sala de reuniões da Unidade de Atenção Primária à Saúde (UAPS) da comunidade, em dias úteis e horários pré-estabelecidos.

Porém, após a realização de 12 entrevistas na UAPS, obtivemos uma parcela considerável de ausências. Os homens relataram que, no horário agendado, estavam na 'roça' trabalhando e, por esse motivo, não puderam comparecer. Foi necessária então, uma readequação na metodologia de coleta dos dados, passando os pesquisadores a entrevistarem os homens em seus locais de tra- 
balho. Os depoimentos foram gravados em áudio, tendo duração média de 50 minutos. Cada homem recebeu a sigla HTR e um número sequencial.

Os dados foram analisados de acordo com a técnica proposta por Minayo (2014), utilizando dois níveis de interpretação. No primeiro nível, foram mapeadas todas as informações coletadas nos prontuários dos entrevistados e as anotações do diário de campo, sendo possível detalhar os processos de trabalho e as características clínico-epidemiológicas dos trabalhadores rurais no sentido de conhecer um pouco mais sobre eles.

No segundo nível de interpretação, foram organizados os documentos elaborados no mapeamento das informações e houve a realização da transcrição das gravações das entrevistas, constituindo o corpus tecnicamente trabalhado. Em seguida, realizamos a leitura horizontal e exaustiva dos textos e a construção das categorias empíricas, além da leitura transversal de cada subconjunto dos dados, por meio das variáveis teóricas adotadas no estudo (Atributos da APS com foco na saúde do homem e os Marcadores Sociais e Interseccionalidades de gênero e classe).

A pesquisa foi aprovada pelo parecer n. 1.374.183, de 17/12/2015, emitido pelo Comitê de Ética da Fundação Oswaldo Cruz - Escola Nacional de Saúde Pública Sergio Arouca (Fiocruz/ENSP). Todos os entrevistados assinaram um termo de consentimento livre e esclarecido após os pesquisadores responderem a todas as suas dúvidas. Para a utilização dos dados dos prontuários e do espaço para as entrevistas, foi assinado um termo de anuência pela gestora de saúde. A pesquisa contou com financiamento próprio, não existindo conflitos de interesses.

O material empírico foi analisado por meio do cruzamento das informações produzidas pelos diferentes procedimentos metodológicos adotados. Essa ação permitiu a construção de quatro categorias temáticas. Do total, duas categorias foram voltadas para as necessidades de saúde: 'aumento no fornecimento de medicamentos' e 'acesso a exames especializados e específicos para a próstata'. As outras duas foram relativas às reivindicações sociais: 'reconhecimento como usuários do serviço de saúde' e 'grupos de educação em saúde com temáticas masculinas'.

\section{Resultados e discussão}

Para discutir os paradigmas de interpretação da realidade frente à compreensão das principais necessidades e reivindicações dos homens trabalhadores rurais, tornou-se indispensável localizarmos a relação sujeito-objeto como questão central da pesquisa. As anotações do diário de campo possibilitaram reconstruir as experiências vivenciadas no território com base nas observações realizadas durante o contato com os entrevistados e as narrativas produzidas durante esses encontros. 
Na região pesquisada, o trabalho rural é desenvolvido em pequenas propriedades e em um período específico do ano, chamado de 'chuvoso', nos meses de outubro a março. O processo de produção inicia com a seleção das sementes e a limpeza da área para o plantio, com a utilização de instrumentais simples como enxada, foice e machado. Por meio do arado manual, ocorre o preparo da terra, na qual as sementes são plantadas em covas abertas pelas enxadas e com o auxílio da máquina 'pé de grilo' ou 'matraca'. São utilizadas formas de produção de alimentos sustentáveis, livre de agrotóxicos. Os principais alimentos produzidos são: feijão, milho, mandioca e abóbora.

A faixa etária de homens selecionados para a entrevista e que desenvolvem exclusivamente o trabalho rural foi de 40 a 60 anos, dentre os quais a maioria tinha o ensino fundamental incompleto. Na região, é comum a migração de homens jovens em busca de emprego nos grandes centros urbanos como Montes Claros, Belo Horizonte e São Paulo. Alguns homens procuram, também, a região do Sul de Minas Gerais para trabalharem na plantação e colheita do café. De acordo com Ramalho e Silveira Neto (2012), os homens jovens são sempre a maioria entre os migrantes na rota rural-urbana. Esses trabalhadores rurais, dotados de baixa instrução, dirigem-se para as grandes cidades à procura de um emprego temporário no setor informal até a fixação no setor formal.

Todos os entrevistados relataram ser autônomos e não ter vínculo com a Previdência Social. O trabalho rural é desenvolvido de segunda a sábado, de $07 \mathrm{~h}$ às $17 \mathrm{~h}$, com pausa de uma a duas horas para o almoço. Essa jornada semanal totaliza, em média, 48 horas e o rendimento mensal em torno de um salário mínimo. Segundo o Departamento Intersindical de Estatística e Estudos Socioeconômicos (Dieese, 2013), a baixa escolaridade, aliada à situação de informalidade, traduz-se, quase sempre, em baixa remuneração.

$\mathrm{O}$ fato de residir em zona exclusivamente rural torna o trabalhador mais propenso a aceitar um vínculo de trabalho não formal. Por outro lado, a migração, os trabalhos de curta duração e o fato de muitos migrantes serem agricultores familiares, que vendem sua força de trabalho em determinados períodos do ano, contribuem para o elevado percentual de trabalhadores informais com local de residência em áreas rurais (Dieese, 2013).

A análise dos dados secundários ocorreu por meio do acesso às informações dos prontuários e fichas de cadastro dos usuários na UAPS. Em relação às características clínico-epidemiológicas, o número total de consultas médicas resultou numa média de 0,08 consulta/homem/ano. Do total de entrevistados, cinco estavam apenas cadastrados nas fichas dos ACS, não possuindo prontuário aberto ou consulta médica registrada. A análise dos prontuários evidenciou os cinco principais motivos de consulta: hipertensão arterial; dores lombares; infecções respiratórias agudas; parasitoses intestinais e acidentes com animais peçonhentos. 
A procura por serviços de saúde pelos homens trabalhadores rurais ainda se apresenta interligada a algum problema, seja agudo ou crônico. Em estudo sobre a atenção à saúde dos homens, Moura et al. (2012) analisaram dados do Sistema de Informações Ambulatoriais do SUS (SIA/SUS) referentes ao ano de 2010. O número total de consultas médicas para homens entre 20 e 59 anos de idade resultou em uma média de 0,06 consulta/homem/ano. Esses valores estão bem próximos aos encontrados no presente estudo.

Em oito prontuários, os médicos registraram a solicitação, 'a pedido' do paciente, de exames especializados como ultrassom, endoscopia e até exames de alta complexidade, como a tomografia. Na maioria das condutas, foram prescritos anti-inflamatórios, analgésicos, antibióticos, antialérgicos e antiparasitários. Do total, quatro homens foram encaminhados para o ortopedista e três para o cardiologista.

Ainda durante o acolhimento dos homens na UAPS, foram relatados nos prontuários outros motivos de procura ao serviço de saúde, com destaque para os atendimentos odontológicos e a busca por medicamentos e vacinação. Um dado que chamou a atenção foi o baixo comparecimento dos homens aos grupos de educação em saúde desenvolvidos pela equipe. No período de julho de 2015 a julho de 2016, estiveram presentes três homens nessas atividades, e apenas um era participante do estudo.

De acordo com Couto et al. (2010), a presença dos homens nas unidades de saúde aumenta em determinadas atividades, especialmente nas consultas médicas, atendimentos em odontologia e atividades disponibilizadas em alguns dos serviços, como: a fisioterapia; o programa de tuberculose e hanseníase; e a saúde mental. Os homens participam menos das atividades educativas. Segundo Moura et al. (2012), dados da Pesquisa Nacional por Amostra de Domicílios (PNAD/2008) apontaram que as principais razões referidas pela população em geral para a busca de atendimento médico foram: doenças (50\%), seguidas por puericultura, vacinação ou outros atendimentos de prevenção $(22 \%)$ e problemas odontológicos (14\%).

Para avançar na compreensão das necessidades e reinvindicações dos homens trabalhadores rurais, priorizamos, a partir desse momento, as informações resultantes dos diálogos com os entrevistados, apresentando as quatro categorias temáticas do estudo.

\section{Necessidade 1: Aumento no fornecimento de medicamentos}

Um dos componentes da assistência farmacêutica no SUS é o fornecimento de medicamentos essenciais para atender às necessidades de saúde consideradas prioritárias para a população brasileira, por meio de farmácias inseridas nas UAPS. A principal necessidade de saúde relatada pelos homens pesquisados diz respeito a esse aspecto: 
[...] Eu vou mais no posto de saúde é para pegar os remédios que preciso. Aqueles para uma dor nas costas, uma dor de cabeça, uma gripe. Eles são muito importantes para nós (HTR-4).

A gente que trabalha e que tem filho pequeno sempre precisa de algum remédio em casa. Aqui, a população adoece muito e precisa demais deles [medicamentos]. Lá no posto, eles até que dão [...] então, eu sempre vou lá buscar (HTR-11).

Em relação ao uso da farmácia dos serviços de saúde do SUS, Figueiredo (2008) destaca, em sua tese, que a farmácia é reconhecida pelos próprios profissionais os quais atuam no setor como um espaço bastante utilizado pela população masculina, que busca, com muita frequência, por medicamentos para si ou para outras pessoas. Couto et al. (2010) também observaram, em seu estudo, um número expressivo de homens que procuram por esses serviços nas UAPS.

Existem evidências de que o fornecimento público é a única forma de acesso a medicamentos para famílias de menor renda, a exemplo das famílias do território pesquisado. Quando a população não consegue acesso gratuito aos medicamentos prescritos pelo médico, principalmente os de uso contínuo, essa situação pode levar ao comprometimento do orçamento familiar (Barreto et al., 2015; Nascimento et al., 2017). Outra questão colocada por Helfer et al. (2012) é o abandono do tratamento pela não aquisição gratuita desses medicamentos, o que acaba agravando ainda mais o estado de saúde e aumentando o número de retornos desses usuários aos serviços.

[...] Até que a prefeitura manda uns remédios aqui para a roça. Mas às vezes, aquele que está precisando não vem [...] então a gente tem que comprar ou ficar sem tomar (HTR-37).

Tem vez que nem o dinheiro para comprar a gente está tendo. E se consultar e não tomar os remédios, não vai resolver! Então, a gente tem que fazer umas economias para comprar [...] deixar de comprar um produto de limpeza ou até mesmo uma carne (HTR-18).

De acordo com pesquisa realizada no Brasil por Mendes et al. (2014), a proporção de UAPS com disponibilidade total de medicamentos, segundo a Relação Nacional de Medicamentos Essenciais, foi maior nos municípios com mais de 500 mil habitantes em relação àqueles com menos de 10 mil habitantes, que são exatamente os municípios que possuem um maior número de comunidades rurais. Essa diferença ficou clara, principalmente, para os grupos de medicamentos mais utilizados pelas equipes de APS, como os contraceptivos $(53,5 \%$ vs $29,5 \%)$, antiparasitários $(14,6 \%$ vs $3,3 \%)$, antiasmáticos $(34,6 \%$ 
vs $18,9 \%)$, antidiabéticos ( $53,5 \%$ vs $41,3 \%)$, anti-infecciosos $(2,0 \%$ vs $1,1 \%)$ e psicotrópicos $(52,0 \%$ vs $42,7 \%)$.

Burille e Gerhardt (2013) destacam que, de acordo com os princípios doutrinários do SUS, a assistência deve ser equitativa e universal. No entanto, no cotidiano dos serviços de saúde, observa-se uma lacuna com relação às ações e às práticas de saúde voltadas para os homens. O sistema de saúde deve se organizar para atender às particularidades da população masculina e ofertar ações compatíveis com as suas necessidades. Nesse sentido, Miranda, Oliveira e Vasconcellos (2018) reforçam que os serviços de Atenção Primária à Saúde, localizados em zona rural, devem direcionar sua atuação para as demandas específicas e os problemas de maior prevalência desses territórios, incluindo a saúde do homem e do trabalhador rural.

Para os homens trabalhadores rurais, a satisfação em relação aos medicamentos vai além do seu fornecimento. Conforme alguns relatos, o aumento na variedade de medicamentos também se apresenta como uma necessidade de saúde:

[...] Outro dia, nem o remédio da pressão e do coração estava tendo. O povo aqui precisa de outros remédios e não é só um paracetamol ou aqueles para tosse (HTR-39).

Lá no posto, tem mais é aqueles [medicamentos] mais simples. Aí, quando o médico passa um mais forte, para resolver um problema mais sério, não tem! Se for para comprar $[\ldots]$, a gente prefere comprar aqueles que não precisam de receita [...] (HTR-1).

A baixa variedade de medicamentos em equipes de saúde situadas em zona rural representa um grande desafio para a integralidade do cuidado. De acordo com Gomes (2011), a integralidade na saúde do homem deve se relacionar de forma harmoniosa entre a organização das políticas e práticas de saúde. Nesse sentido, os princípios orientadores são o acolhimento às principais necessidades dos usuários e a ampliação do foco do adoecimento com base nas questões relacionadas à vida cultural e social.

Como parte do direito constitucional à saúde, em 1998, os serviços farmacêuticos no SUS passaram a ser organizados pela Política Nacional de Medicamentos, que visa a garantir uma variedade de medicamentos destinados a apoiar as ações de saúde de forma integral e regionalizada (Nascimento et al., 2017). De acordo com Di Cesare et al. (2017), no Brasil, apesar de ser direito à saúde, o acesso a medicamentos essenciais para prevenir e tratar doenças de alta prevalência, como as cardiovasculares, respiratórias crônicas e diabetes, ainda pode ser considerado baixo e irregular.

Em uma análise marxista, o papel extratécnico dos medicamentos diz respeito à extrapolação de sua ação farmacológica e passa a ser associado ao 
valor de uso e ao valor de troca (Barros, 2002). A dominação do capitalismo na saúde tem estimulado, intensamente a valorização de modelos assistenciais que visam à cura. De acordo com Esher e Coutinho (2017), o crescimento excessivo no uso de medicamentos, em muitos países, tem sido apontado como uma importante barreira ao alcance do uso racional de medicamentos e faz parte de um fenômeno denominado 'farmaceuticalização' da sociedade. A farmaceuticalização é definida pelo uso excessivo e sem prescrição médica de medicamentos para melhorar o estilo de vida, o trabalho, a cognição e o desempenho sexual entre pessoas saudáveis.

Embasados culturalmente em uma concepção de cuidar da saúde relacionada, diretamente, à interferência química dos medicamentos sobre os sinais e sintomas das doenças, os homens trabalhadores rurais acabam hipervalorizando as funções que tais medicamentos podem desempenhar. Ocorre, também, a produção de uma dependência pelo fato de acreditarem que, para todo e qualquer problema de saúde, independentemente de sua gravidade ou nexos causais, existirá o que Barros (2002) chama de um 'comprimido salvador'.

Os serviços de saúde podem, e devem, construir estratégias assistenciais para melhoria do atendimento às diferentes necessidades de saúde que o público masculino apresenta (Burille, 2012). Essas necessidades remetem a um processo histórico e social, construído com base no cotidiano desses homens (Gerhardt, et al., 2009). Existe uma grande complexidade na relação entre as necessidades de saúde e o desenvolvimento político, econômico e social brasileiro.

De acordo com Gadelha et al. (2011), nesse cenário, é fundamental que os investimentos do Estado estimulem a formulação de políticas públicas mais equânimes, que reconheçam a saúde como direito e que priorizem as necessidades como categoria essencial para as formas de justiça social. A análise da dimensão territorial mostra-se necessária, condicionando e sendo condicionada pelas ações de saúde, uma vez que é no espaço, em suas diversas escalas, que as políticas públicas de saúde se encontram e são colocadas em prática. Na realidade, a estruturação da rede de saúde depara-se com o desafio de articular diferentes localidades que, pelo grau de concentração dos serviços e de sua complexidade, demandam um maior equilíbrio e articulação entre as políticas sociais e econômicas (Gerhardt et al., 2009).

Necessidade 2: Acesso a exames especializados e específicos para a próstata

As narrativas permitiram a compreensão de outra necessidade de saúde: o acesso a exames especializados na rede de serviços do SUS. O fluxo de regulação desses exames inicia-se nas UAPS, com a avaliação e solicitação pelos médicos para a realização dos procedimentos. 
Quando estou sentido alguma coisa mais grave, consulto lá no posto de saúde e os médicos já pedem uns exames mais completos [especializados]. A gente precisa muito desses exames que veem o que a gente sente por dentro (HTR-22).

No Brasil, a atenção secundária ou de média complexidade tem, entre suas funções, a oferta ao nível microrregional de exames especializados como ultrassonografias, endoscopias, ecocardiogramas, entre outros (Yonekura, 2016). Competem aos municípios, por meio das Secretarias Municipais de Saúde, a pactuação, faturamento, regulação e autorização desses procedimentos, e às equipes de APS, a responsabilidade de regular os fluxos de usuários, por meio de instrumentos que garantam uma referência eficaz aos níveis de maior complexidade da Rede de Atenção à Saúde.

O médico passou um ultrassom e uma endoscopia para eu fazer. A menina [Agente de Saúde] falou para eu ir autorizar lá na cidade [Secretaria de Saúde]. Esses exames são muito caros e se eles [médicos] pedem é porque a gente está precisando fazer. O ruim é que demora demais para eles marcarem e até a gente conseguir fazer o problema só vai piorando (HTR-16).

De acordo com Yonekura (2016), em quase três décadas de criação do SUS, não existem ainda diretrizes operacionais claras e recursos financeiros apropriados para impulsionar a ampliação e a estruturação da atenção especializada. São muitos os gargalos; neste estudo, destacamos a grande dificuldade que as populações rurais enfrentam para o acesso e realização desses procedimentos. Gaspodini (2017) coloca que o baixo poder aquisitivo e a classe social são razões comuns para a discriminação nos serviços de saúde, interferindo, diretamente, nos cuidados à saúde. Nesse sentido, não podemos desconsiderar a relação entre renda, classe social e demais marcadores sociais de desigualdade, nas análises sobre as necessidades de saúde desses homens.

Para Guimarães (2002), os marcadores baseados na desigualdade social impactam diretamente no acesso à informação, e na aquisição de conhecimentos que possibilitem que homens e mulheres realizem enfrentamentos, argumentem e se defendam da dominação do Estado. Estudos de Kageyama (2008) e Albuquerque e Cunha (2012) demonstram que a pobreza é mais severa nas áreas rurais. Os autores destacam que tal fato ocorre pela ausência ou precariedade nessas áreas de serviços de educação, saúde, saneamento básico, dentre outras dimensões analisadas pelos indicadores de pobreza multidimensional. Essa situação social coloca a população residente nas áreas rurais em uma condição de maior vulnerabilidade em relação à população que reside em áreas urbanas.

Na saúde, a dificuldade para a garantia de acesso a serviços especializados para as populações rurais decorre, principalmente, dos modelos de gestão e 
atenção implantados e da resolutividade da APS nesses territórios (Miranda, Oliveira e Vasconcellos, 2018). Especificamente sobre a resolutividade da APS, Starfield (2002) destaca que um sistema de saúde orientado para a subespecialização ameaça gravemente os objetivos da equidade em saúde em nível mundial. A atenção especializada é, comprovadamente, mais cara e, portanto, menos acessível para os indivíduos, sejam eles regulados pelo SUS ou por acesso direto ao sistema privado (Yonekura, 2016; Nascimento et al., 2017).

Percebe-se que outra necessidade para o cuidado à saúde do homem trabalhador rural encontra-se vinculada diretamente ao exame preventivo do câncer de próstata:

Tem que ter aquele exame de sangue para a próstata! Porque se o homem descobrir alguma coisa [doença], já procura logo um especialista (HTR-7).

[...] Os exames de próstata são muito importantes. Tem aquele do dedo, mas nunca fiz não [pausa]. Estou precisando dele! Meu vizinho fez também um ultrassom para esse problema. São essas coisas que mais precisamos aqui (HTR-13).

De acordo com Cavalcanti et al. (2014), devido ao modelo hegemônico da masculinidade e à grande divulgação na mídia e nos discursos populares, o exame preventivo do câncer de próstata tornou-se uma grande necessidade por parte dos homens brasileiros, os quais acreditam que a saúde do homem está relacionada, principalmente, à realização anual desse exame. A Sociedade Brasileira de Urologia recomenda o rastreamento de neoplasia maligna de próstata pela dosagem anual no sangue do antígeno prostático específico, conhecido como PSA, e o toque retal em homens entre 50 e 80 anos. Nos homens com parentes de primeiro grau com diagnóstico de câncer de próstata, o rastreamento pode começar aos 45 anos (SBU, 2014).

Modesto et al. (2018) destacam que essas 'recomendações' da Sociedade Brasileira de Urologia (SBU) são, por sua vez, um tanto ambíguas. Existem controvérsias e posições conflitantes sobre esse rastreamento entre a SBU, o Ministério da Saúde (MS) e o Instituto Nacional do Câncer (INCA). Em 2010, o MS publicou que o nível de evidência de estudos na área ainda era insuficiente para indicar recomendações a favor ou contra o rastreamento do câncer de próstata em homens com menos de 75 anos. Em homens mais velhos, o screening já era contraindicado. Essas recomendações foram alinhadas às do European Observatory on Health Systems and Policies (EOHSP). Em junho de 2015, o MS e o INCA publicaram uma nota conjunta, reafirmando-se contrários ao rastreamento populacional do câncer de próstata, considerando que os potenciais malefícios superam seus potenciais e questionáveis benefícios.

Existem outros problemas graves que estão relacionados à saúde do homem e que não são evidenciados rotineiramente por eles (Couto et al., 2010; 
Gomes, 2011). Para evitar o reducionismo de pensar a saúde do homem apenas pela próstata, temos que destacar os eixos geradores de todas essas diferenças entre os homens. De acordo com Connell e Messerschmidt (2013), existe uma geografia das masculinidades com especificidades locais e regionais que influenciam o modo de pensar e de se comportar dos homens. Ao adotarmos essa estrutura analítica que distingue esses níveis, reconhecemos e valorizamos a importância que cada território apresenta para a formação das diferentes masculinidades. As noções de masculinidade compartilhadas no território pesquisado misturam-se com a concepção do trabalho rural.

Foram observadas características culturais enraizadas em aspectos regionais da cultura norte mineira, que reforçam as formas de ser, agir e cuidar da saúde por esses homens. Para Scott (1995), a categoria gênero apresentase como um dos principais elementos articuladores das relações sociais, e é o que possibilita entender como os sujeitos sociais são constituídos no cotidiano, impregnados em um emaranhado de significados e símbolos culturais e subjetividades sexuadas. Ainda de acordo com a autora, esses elementos atribuem a homens e mulheres lugares diferentes na sociedade, na família e no trabalho.

\section{Reivindicação 1: Reconhecimento como usuários do serviço de saúde}

Entre os entrevistados, 36 homens relataram apresentar grande dificuldade ao acesso e ao atendimento na UAPS local, tendo como principal reivindicação o seu reconhecimento como usuários do serviço de saúde. Durante a compreensão dessa reivindicação, surgiram questões centrais como as desigualdades e injustiças sociais presentes nesse território rural.

A gente aqui é meio que invisível para eles [profissionais de saúde]. Quem trabalha na roça é como se não tivesse importância na saúde (HTR-6).

O homem aqui é muito esquecido! Eu só vejo as coisas da saúde quando a menina [ACS] passa lá em casa. E ela vai mesmo é para conversar com a minha avó que tem pressão alta (HTR-38).

Para essa análise, utilizaremos os marcadores sociais, refletindo, especificamente, sobre como as desigualdades sociais são produto das relações estabelecidas entre os indivíduos, no conflito de interesses em relação a outros indivíduos ou grupos. Nos discursos, identificamos a existência de marcadores sociais de classe, que vão além de questões de gênero, e como eles afetam as práticas de saúde e produzem vulnerabilidades nesse território. Esses homens são marcados por sua classe social, cultura regional, idade, condições de trabalho e distribuição desigual de renda. 
De acordo com Sagesse et al. (2018), no debate teórico sobre classes sociais, diferentes critérios vêm sendo mobilizados para definir posições no espaço social economicamente estratificado. Este espaço é definido pela propriedade dos meios de produção, renda, ocupação, consumo de bens e práticas culturais. Desta forma, para a compreensão dos âmbitos políticos, econômicos e ideológicos, torna-se necessário recorrer à elaboração de um raciocínio dialético que articule gênero e classe, categorias que estruturam as relações de poder e transcendem o econômico.

Moura et al. (2014) destacam que os homens possuem os mesmos direitos de atenção qualificada que os outros públicos na APS. Porém, eles não têm suas especificidades reconhecidas e não fazem parte das populações usualmente mais assistidas nos serviços de saúde da família. Infelizmente, essa realidade é uma consequência histórica da priorização da população feminina e infantil pelo setor de saúde brasileiro e também pela dificuldade de verbalização pelos homens das suas próprias necessidades de saúde (Cavalcanti et al., 2014; Moura et al., 2014).

Os serviços da APS acabam não valorizando e planejando ações para a saúde do homem, na lógica organizacional da promoção da saúde e da prevenção de doenças. Essa forma de invisibilidade é reforçada mais pela incapacidade apresentada pelas equipes de saúde situadas em zona rural, frente à realização de uma análise crítica, que vise a reconhecer as principais reivindicações dos trabalhadores rurais para além de uma consulta médica:

Tem vez que vou no posto de saúde e a menina [recepcionista] fica fazendo hora com a gente $[\ldots]$ demora muito para atender. Parece que aqui o homem não tem direito de ficar doente e procurar por atendimento (HTR-5).

Quando chego lá, já perguntam se eu quero é uma ficha para passar com o médico. Não esperam nem eu falar o que fui fazer. Eles [equipe] tratam a gente muito ruim (HTR-11).

De acordo com Bilge (2009), a interseccionalidade aborda a complexidade das identidades e das desigualdades sociais por intermédio de um enfoque integrado. O enfoque interseccional vai além do simples reconhecimento da multiplicidade dos sistemas de opressão que operam nessas categorias e postulam sua interação na produção e na reprodução das desigualdades sociais. Crenshaw (2004) destaca que, na verdade, nem sempre lidamos com grupos distintos de pessoas e sim com grupos sobrepostos. Para explicar a interseccionalidade, a autora usa a noção de eixos ou de ruas que se entrecruzam, de modo a identificar diversas formas de discriminação que se combinam e afetam determinadas pessoas. 
As discussões sobre classe social contribuem para uma análise sobre a distribuição de ações de saúde em determinada sociedade. Existe uma posição de maior vulnerabilidade desses homens frente ao processo saúde-doençacuidado em relação a mulheres, idosos e crianças do território. Para alguns autores, como Barata (2009) e Gaspodini et al. (2017), não há, na sociedade, apenas um tipo de opressão ou dominação; ao contrário, existe uma multiplicidade de fenômenos que circundam as relações sociais entre homens e mulheres, expressos por diferentes tipos de comportamento.

As categorias gênero e classe, além de permitirem compreender as relações de poder e dominação que perpassam o trabalho no meio rural, podem ser instrumentos analíticos para a compreensão das desigualdades e assimetrias entre a saúde dos trabalhadores rurais e, principalmente, as suas reivindicações (Sagesse et al., 2018). Existe uma sobreposição ou intersecção de identidades sociais e sistemas relacionados à opressão, dominação ou discriminação desses trabalhadores pelo serviço de saúde local. Essas diferenças sociais podem ser produtos das relações estabelecidas entre indivíduos, famílias, comunidade e profissionais de saúde.

Couto et al. (2010) colocam que alguns homens não encontram nos serviços públicos de saúde uma escuta qualificada para suas demandas, especialmente se forem expressas de forma diferente daquelas reconhecidas pelo modelo assistencial curativista, como as queixas urológicas. Segundo Burille (2012), para uma atuação na APS, é fundamental o conhecimento das maneiras de ser e fazer dos coletivos, em específico, do coletivo masculino. Devem ser identificadas as práticas relacionadas direta e indiretamente às suas reivindicações e os caminhos para a incorporação de novos olhares na lógica dos serviços de saúde.

De acordo com Acioli (2006), os indivíduos vêm desenvolvendo movimentos, muitas vezes imperceptíveis pelos profissionais de saúde, em relação à compreensão de suas experiências e movimentos em direção às práticas cotidianas de cuidado à saúde. Couto et al. (2010) constataram que alguns profissionais de saúde destinam menos tempo de seu atendimento e atenção às queixas dos homens, oferecendo breves explicações sobre suas demandas e problemas, quando comparados às mulheres, que teriam um atendimento mais detalhado e demorado.

Nós temos direito, sim! E não é só de consultar. Tem o direito de tratar dos dentes, de tomar as vacinas, de ir lá buscar mais informações sobre as coisas que estiver sentindo ou precisando. A gente também adoece (HTR-19).

A saúde é para todo mundo, né? O homem que trabalha na roça também paga os impostos. Então, tem que lutar por mais coisas para nossa saúde (HTR-6). 
Miranda, Oliveira e Vasconcellos (2018) colocam que o direito à saúde, apesar de ser considerado como um direito constitucional, ainda não está totalmente garantido para os homens trabalhadores rurais, o que impõe uma luta permanente para sua conquista. As desigualdades sociais existentes no campo influenciam, diretamente, o processo saúde-doença e manifestam-se de maneira diversa entre os homens, mulheres e suas famílias no acesso e utilização de serviços de saúde pública em locais rurais.

Na contramão do pensamento biomédico, a maioria dos homens entrevistados relatou uma forte movimentação no sentido de lutarem pelo seu direito à saúde. Barata (2009) destaca que diferentes populações atribuem maior ou menor importância ao direito à saúde como um direito humano fundamental. Reconhecer as desigualdades sociais é buscar compreender os processos que as produzem, e identificar os diferentes aspectos que contribuem para a luta por melhores condições de saúde.

\section{Reivindicação 2: Grupos de educação em saúde com temáticas masculinas}

Outra reivindicação apresentada pela maioria dos entrevistados foi relacionada à organização e desenvolvimento de grupos educativos com temáticas voltadas, especificamente, para a saúde do homem. A educação em saúde com foco no público masculino deve representar um espaço de prática e conhecimento, promovendo a relação entre o pensar e o fazer no cotidiano de vida e trabalho.

O homem que trabalha na roça é muito descaprichoso. Eu tiro por mim mesmo, que só procuro o posto de saúde quando preciso passar [consultar] com o médico. A gente tinha que ter umas palestras [...] (HTR-24).

[...] Até que nas consultas o médico fala para a gente estar cuidando da saúde. Mas quando reúne mais gente, fica melhor para a gente falar desses problemas (HTR-2).

Nessa direção, a educação em saúde promove, por meio de um conjunto de práticas pedagógicas e sociais, a formação da consciência crítica no que diz respeito à política de saúde (Monteiro e Vieira, 2010). A prática da educação em saúde na APS deveria acontecer com maior ou menor profundidade, em todas as relações terapêuticas que envolvam o processo saúde-doença, ou seja, no cotidiano das equipes. Para Sevalho (2018), um atendimento individual pode e deve ser um momento rico de aprendizagem; porém, é nos grupos que há condições mais propícias ao seu desenvolvimento, com a troca de experiências entre os participantes. 
Se tivessem essas reuniões [para os homens], ia ser muito bom. Às vezes, um problema que meu vizinho está passando é o mesmo que o meu [...] e assim, a gente já fica mais preparado para resolver (HTR-4).

Para promover o empoderamento desses homens, tanto em nível individual quanto coletivo, torna-se imprescindível o desenvolvimento de ações educativas pelas equipes de APS. Essas atividades devem ser desvinculadas de uma prática educacional impositiva e tradicional, reduzida apenas a atividades teóricas que se reportam em transmitir informação em saúde. Paulo Freire (1987) nos ensina que a educação como um processo dinâmico deve envolver a tríade ação-reflexão-ação. As atividades de grupo para esses homens representam uma oportunidade singular de repor a questão da saúde durante o seu processo produtivo, aprofundando aprendizados e fortalecendo o cuidado em saúde:

Tinha que ter algum encontro para eles [equipe de saúde] falarem dos problemas para nós [homens]. A gente tem que saber mais sobre como evitar essas coisas ruins [doença] (HTR-37).

Faz-se necessário um olhar direcionado para o conhecimento social e epidemiológico dos problemas que acometem ou poderão acometer esses homens trabalhadores rurais, para, assim, pensar em medidas educativas eficazes no atendimento de suas reivindicações. O Círculo de Cultura apresenta-se como uma proposta de (re)construção dessas ações de educação em saúde e pode ser muito útil nessa abordagem. De acordo com Freire (1987) e Salci (2013), essa metodologia permite a construção de um espaço dinâmico de aprendizagem e de troca de conhecimentos entre os participantes, por meio de investigações de temas de interesse do próprio grupo.

Conforme Monteiro e Vieira (2010), o desenvolvimento do trabalho educativo com a aplicação do Círculo de Cultura requer atenção para todos os aspectos do território e dos participantes. As falas, as conversas, as frases, as entrevistas, as discussões, dentro ou fora do círculo, tudo está carregado dos temas da comunidade, seus assuntos, sua vida. Tomando por princípio norteador o delineamento do 'Método Paulo Freire', o desenvolvimento do Círculo consiste em três momentos: a investigação temática; a tematização, mediante a qual se codificam e decodificam os temas identificados; e a problematização, por meio de uma visão crítica, partindo para a transformação do contexto vivido (Freire, 1987).

Para a utilização dessas abordagens ativas e dialógicas de educação em saúde, faz-se necessária uma mudança na conduta dos profissionais que integram as equipes de APS e, principalmente, das equipes de saúde da família 
no campo. Devem ser rompidos os padrões comportamentais autoritários, característicos de metodologias tradicionais de educação em saúde. Essa relação entre educação em saúde e a pedagogia libertadora proporcionará, a longo prazo, um diálogo horizontalizado entre os profissionais de saúde e os homens trabalhadores rurais.

\section{Considerações finais}

Este artigo apresenta elementos importantes para avançarmos na discussão de modelos ampliados de cuidado à saúde com foco nas necessidades de saúde e nas reivindicações sociais elencadas pelos homens trabalhadores rurais. Por meio das narrativas, foi possível compreender que existem dificuldades de acesso aos serviços ofertados pela APS do território, apresentando relação direta com os marcadores sociais de gênero e classe e as suas interseccionalidades na busca por cuidados à saúde.

Essa situação contribui ainda mais para o fortalecimento e a valorização de um modelo assistencial curativista, cuja farmaceuticalização e a grande dependência por exames especializados e específicos para a próstata apresentam-se como as principais necessidades de saúde. Por outro lado, as reivindicações declaradas fortalecem os movimentos de luta desses homens pelo reconhecimento do direito social à saúde. Essa luta é percebida e reforçada, diariamente, pelas experiências vivenciadas e construídas na procura pelos atendimentos disponibilizados pela equipe de saúde.

É perceptível que as ações de saúde ofertadas pela APS para o público masculino ainda enfrentam muitos desafios para a sua efetividade, equidade e universalidade. Compreender as posições de dominação envolvidas nessa disputa é o primeiro passo para desvendar modos de ação que sejam eficazes no combate à invisibilidade desse público pelos serviços de saúde. Reafirmar a participação masculina na luta pela saúde como direito é uma das possibilidades de construção coletiva e emancipatória. É preciso promover incentivos ao homem rural para que ele possa comparecer, preventivamente, às unidades de saúde e construir um vínculo que gere adesão às atividades educativas.

Nessa perspectiva, as políticas públicas de saúde para a população do campo devem ser articuladas de forma mais integrada com a situação de saúde de cada território, iniciando com a escuta qualificada de todas as demandas apresentadas pela população adscrita no intuito de melhor atendê-las. Estratégias como essas visam à mudança na lógica da organização dos serviços de saúde no campo e contribuem para o empoderamento dos homens trabalhadores rurais frente aos cuidados em saúde. 


\section{Colaboradores}

Sérgio Vinícius Cardoso de Miranda e Luiz Carlos Fadel de Vasconcellos participaram ativamente da concepção da pesquisa, estruturação, levantamento bibliográfico, metodologia, coleta dos dados, análise e interpretação dos dados e discussão dos resultados, redação do artigo e aprovação da versão final. Pâmela Scarlatt Durães Oliveira e Virlady Cardoso de Miranda Moraes participaram do levantamento bibliográfico, apoio de campo na coleta dos dados, discussão dos resultados e revisão final do texto.

\section{Financiamento}

Sérgio Vinícius Cardoso de Miranda recebeu bolsa de mestrado do Ministério da Saúde, por meio do Departamento de Apoio à Gestão Participativa (DAGEP/SGEP).

\section{NECESIDADES Y RECLAMACIONES DE LOS TRABAJADORES RU- RALES EN MATERIA DE ATENCIÓN PRIMARIA DE SALUD}

Resumen El objetivo fue comprender las principales necesidades y reclamaciones de los trabajadores rurales ante un equipo de Atención Primaria de Salud en sudeste de Brasil. Se trata de un estudio cualitativo, guiado por el enfoque hermenéutico-dialéctico. Se realizaron 41 entrevistas en profundidad, registros diarios de campo y recopilación de datos secundarios. En el análisis se utilizaron los niveles de interpretación, permitiendo la construcción de dos categorías temáticas para las necesidades de salud: "aumento del suministro de medicamentos" y "acceso a exámenes especializados y específicos de próstata". También se desarrollaron dos categorías para reivindicaciones sociales: "reconocimiento como usuarios del servicio de salud" y "grupos de educación sanitaria con temas masculinos". La discusión se basó en los atributos de la Atención Primaria de Salud y en la Teoría de Marcadores Sociales e Interseccionalidades. El estudio permitió comprender el proceso productivo, conocer las características clínicas y epidemiológicas y discutir la invisibilidad de los trabajadores rurales en la búsqueda y acceso a los servicios de salud. Observamos una apreciación del modelo de medicina curativa y la contribución positiva de las reivindicaciones de los hombres para fortalecer los movimientos que luchan por el derecho social a la salud.

Palabras clave población rural; atención primaria de salud; salud del hombre; necesidades y demandas de servicios de salud. 


\section{Nota}

${ }^{1}$ Para a escrita do referencial teórico e discussão crítica do presente artigo, foram realizadas buscas por meio de uma revisão integrativa nas principais bases de dados em saúde SCIELO, LILACS, MEDLINE, PUBMED, PAHO, WHOLIS, MEDCARIBE - e bibliotecas de teses e dissertações - USP, FIOCRUZ, UFRJ, UFMG, UFBA e UNIFESP. Além do referido material, houve fichamento e utilização de livros clássicos que versam sobre os conteúdos abordados no manuscrito.

Os pesquisadores utilizaram algumas referências com mais de cinco anos de publicação por se tratarem de textos clássicos na área do marxismo, hermenêutica-dialética, educação e trabalho, além da existência de poucos trabalhos publicados nos últimos cinco anos sobre as necessidades de saúde da população brasileira e, principalmente, sobre a saúde do homem com uma visão ampliada sobre o cuidado em saúde e o trabalho rural.

\section{Referências}

ACIOLI, Sônia. Os sentidos das práticas voltadas para a saúde e doença: maneiras de fazer de grupos da sociedade civil. In: PINHEIRO, Roseni; MATTOS, Ruben A. (Orgs). Os sentidos da integralidade na atenção e no cuidado à saúde. 4 ed. Rio de Janeiro: CEPESC/UERJ, ABRASCO, 2006.

ALBUQUERQUE, Marcela R.; CUNHA, Marina S. Uma análise da pobreza sob o enfoque multidimensional no Paraná. Revista de Economia, Curitiba, v. 38, n. 3, p. 45-64, 2012.

BARATA, Rita B. Relações de gênero e saúde: desigualdade ou discriminação? In: Como e por que as desigualdades sociais fazem mal à saúde [online]. Rio de Janeiro: Editora FIOCRUZ, 2009.

BARRETO, Maria N. S. C. et al. Análise do acesso ao tratamento medicamentoso para hipertensão e diabetes na Estratégia de Saúde da Família no Estado de Pernambuco, Brasil. Revista Brasileira de Epidemiologia, São Paulo, v. 18, n. 2, p. 413-24, 2015.

BARros, José A. C. Pensando o processo saúde doença: a que responde o modelo biomédico? Saúde e Sociedade, São Paulo, v.11, n.1, p. 67-84, 2002.
BILGE, Sirma. Théorisations féministes de l'intersectionnalité. Diogène, s.l., v. 1, n. 225, p. 70-88, 2009.

BURILLE, Andréia; GERHARDT, Tatiana E. Conexões entre homens e saúde: discutindo algumas arranhaduras da masculinidade. Athenea Digital, Barcelona, v. 13, n. 2, p. 259-266, 2013.

BURILLE, Andreia. Itinerários terapêuticos de homens em situação de adoecimento crônico: (des) conexões com o cuidado e arranhaduras da masculinidade. 2012. 184 fl. Dissertação (Mestrado em Enfermagem) Universidade Federal do Rio Grande do Sul. Porto Alegre, 2012.

CALDART, Roseli S. et al. Dicionário da Educação do Campo. Rio de Janeiro, São Paulo: Escola Politécnica de Saúde Joaquim Venâncio, Expressão Popular, 2012.

CAMPOS, Célia M. S. Necessidades de saúde pela voz da sociedade civil (os moradores) e do Estado (os trabalhadores de saúde). $193 \mathrm{fl}$. Tese (Doutorado em Enfermagem). Faculdade de Enfermagem, USP, São Paulo, 2004.

CAMPOS, Célia M. S.; MISHIMA, Silvana M. Necessidades de saúde pela voz da sociedade 
civil e do Estado. Cadernos de Saúde Pública, Rio de Janeiro, v. 21, p. 1260-1268, 2005.

CAVALCANTI, Joseane R. D. et al. Assistência Integral a Saúde do Homem: necessidades, obstáculos e estratégias de enfrentamento. Escola Anna Nery, Rio de Janeiro, v. 18, n.4, p. 628-634, 2014.

CONNELL, Robert; MESSERSCHMIDT, James. Masculinidade hegemônica: repensando o conceito. Estudos Feministas, Florianópolis, v. 21, n. 1, p. 241-282, 2013.

COUTO, Márcia T. et al. O homem na atenção primária à saúde: discutindo (in)visibilidade a partir da perspectiva de gênero. Interface: Comunicação, Saúde e Educação, Botucatu, v. 14, n. 33, p. 257-70, 2010.

CRENSHAW, Kimberle. A intersecionalidade na discriminação de raça e gênero. P. 7-16, 2004. Disponível em: http://www.acaoeducativa.org. br/fdh/wp-content/uploads/2012/09/KimberleCrenshaw.pdf. Acesso em: 16 out. 2018.

DI CESARE Mariachiara. et al. Inequalities in non-communicable diseases and effective responses. The Lancet, London, v. 381, n. 9866, p. 585-597, 2013.

DIEESE. O emprego doméstico no Brasil. Estudo e Pesquisa. São Paulo, n. 68. Agosto de 2013. Disponível em: http://www.dieese. org.br/estudosetorial/2013/estPesq68empregoDomestico.pdf. Acesso em: 14 jul. 2016.

ESHER, Ângela; COUTINHO, Tiago. Uso racional de medicamentos, farmaceuticalização e usos do metilfenidato. Ciência \& Saúde Coletiva, Rio de Janeiro, v. 22, n. 8, p. 2571-2580, 2017.

FIGUEIREDO, Wagner S. Masculinidades e cuidado: diversidade e necessidades de saúde dos homens na atenção primária. Tese (Doutorado em Ciências - Medicina Preventiva) Faculdade de Medicina, USP, São Paulo, 295fl., 2008.

FREIRE, Paulo. Pedagogia do oprimido. Rio de Janeiro: Paz e Terra; 1987.
GADAMER, Hans G. Verdade e método. Petrópolis: Editora Vozes, 1999.

GADELHA, Carlos A. G. et al. Saúde e territorialização na perspectiva do desenvolvimento. Ciência e Saúde Coletiva, Rio de Janeiro, v. 16, p. 3003-3016, 2011.

GASPODINI, Ícaro B. et al. Masculinidades em diálogo: produção de sentido a partir de marcadores sociais da diferença. Mudanças - Psicologia da Saúde, São Paulo, v.25, n.1, p. 17-25, 2017.

GERHARDT, Tatiana E. et al. Determinantes sociais e práticas avaliativas de integralidade em saúde: pensando a situação de adoecimento crônico em um contexto rural. In: PINHEIRO, Roseni; MARTINS, Paulo H. (Org.). Avaliação em saúde na perspectiva do usuário: abordagem multicêntrica. Rio de Janeiro: CEPESC, 2009.

GOMES, Romeu. Saúde do homem em Debate. Rio de Janeiro: Editora Fiocruz, 2011.

GUIMARÃES, Antônio S. A. Classes, raças e democracia. São Paulo: Editora 34, 2002.

HABERMAS, Jurgen. Conhecimento e interesse. Rio de Janeiro: Guanabara, 1987.

HELFER, Ana P. et al. Capacidade aquisitiva e disponibilidade de medicamentos para doenças crônicas no setor público. Revista Panamericana de Salud Pública, Washington, v.31, n. 3, p. 225-32, 2012.

HELLER, Agnes. Teoría de las necessidades em Marx. Barcelona: Península, 1986.

INSTITUTO BRASILEIRO DE GEOGRAFIA E ESTATÍSTICA (IBGE) Censo Demográfico 2010. Disponível em: <http://www.censo2010.ibge. gov.br $>$. Acesso em: 23 nov. 2016.

KAGEYMA, Ângela A. Desenvolvimento rural: conceitos e aplicações ao caso brasileiro. Porto Alegre: Editora UFRGS 2008.

MENDES, Luiz V. et al. Disponibilidade de medicamentos nas unidades básicas de saúde 
e fatores relacionados: uma abordagem transversal. Saúde em Debate, Rio de Janeiro, v. 38, p. 109-123, 2014.

MINAYO, Maria C. S. O desafio do conhecimento: pesquisa qualitativa em saúde. São Paulo: Ed. Hucitec, 2014.

MIRANDA, Sérgio V. C.; OLIVEIRA, Pâmela S. D; VASCONCELLOS, Luiz C. F. A visão do homem trabalhador rural norte-mineiro sobre o cuidado em saúde no contexto da atenção primária à saúde. Ciência \& Saúde Coletiva, Rio de Janeiro, ago.2018. Disponível em: $<$ http://www.cienciaesaudecoletiva. com.br/artigos/a-visao-do-homem-trabalhador-ruralnortemineiro-sobre-o-cuidado-em-saude-no-contextoda-atencao-primaria-a-saude/16934?id=16934> . Acesso em: 10 jul. 2019.

MODESTO, Antônio A.D.A. Um novembro não tão azul: debatendo rastreamento de câncer de próstata e saúde do homem. Interface: Comunicação, Saúde e Educação, Botucatu, v. 22, n. 64, p. 251-262, 2018.

MONTEIRO, Estela M.L.M; VIEIRA, Neiva F. C. Educação em saúde a partir de círculos de cultura. Revista Brasileira de Enfermagem, Brasília, v. 63, n. 3, p. 397-403, 2010.

MOURA, Erly C. et al. Atenção à saúde dos homens no âmbito da Estratégia Saúde da Família. Ciência \& Saúde Coletiva, Rio de Janeiro, v. 19, n. 2, p. 429-438, 2014.

MOURA, Erly C. et al. Perfil da situação de saúde do homem no Brasil [relatório]. Rio de Janeiro: Fiocruz; 2012.

NASCIMENTO, Amauri M.; NASCIMENTO, Sonia M. Iniciação ao direito do trabalho. São Paulo: LTr. 2007.

NASCIMENTO, Renata C. R. M. et al. Disponibilidade de medicamentos essenciais na atenção primária do Sistema Único de Saúde. Revista de Saúde Pública. São Paulo, 2017; v. 51, Supl 2:10s, 2017.

PIANA, Maria C. A construção do perfil do assistente social no cenário educacional. São Paulo: Cultura Acadêmica, 2009.
RAMALHO, Hilton M. B; SILVEIRA NETO, R. M. A inserção do migrante rural no mercado de trabalho urbano no Brasil: uma análise empírica da importância dos setores informal e formal. Estudos Econômicos, São Paulo, v. 42, n. 4, p. 731-771, 2012.

SALCI, Maria A. et al. Educação em saúde e suas perspectivas teóricas: algumas reflexões. Texto e Contexto Enfermagem, Florianópolis, v. 22, n.1, p. 224-230, 2013.

SAGESSE, Gustavo S. R. et al. Marcadores sociais da diferença: gênero, sexualidade, raça e classe em perspectiva antropológica. São Paulo: Editora Gramma, 2018.

SOCIEDADE BRASILEIRA DE URULOGIA. Diretrizes urologia $A M B$. Rio de Janeiro: SBU, 2014.

SEVALHO, Gil. O conceito de vulnerabilidade e a educação em saúde fundamentada em Paulo Freire. Interface: Comunicação, Saúde e Educação, Botucatu, v. 22, n. 64, p. 177-188, 2018.

SILVA, C.; PORTELLA, A. P. Divisão sexual do trabalho em áreas rurais no Nordeste brasileiro. In: SCOTT, R. P.; CORDEIRO, R. L. M. (Org.). Agriculturas familiares e gênero: práticas, movimentos e políticas públicas. Recife: UFPE, 2006. p. 127-144.

SILVA, Patrícia A. S. et al. Saúde do homem na visão do enfermeiro. Escola Anna Nery, Rio de Janeiro, v. 16, n. 3, p. 561-568, 2012.

SCOTT, Joan. Gênero: uma categoria útil de análise histórica. Educação e Realidade. Porto Alegre, v. 16, n. 2. p. 5-22, 1995.

STARFIELD, Bárbara. Atenção Primária: equilíbrio entre necessidades de saúde, serviços e tecnologia. Brasília: Ed. UNESCO, Ministério da Saúde, 2002.

YONEKURA, Tatiana. Necessidades de saúde: construção de instrumento para o planejamento regional em saúde. 207fl. Tese (Doutorado em Cuidado em Saúde) - Escola de Enfermagem, USP, São Paulo, 2016. 